\title{
Nomeações e significações da homossexualidade masculina: um ensaio sobre homofobia pela ótica da Teoria das Representações Sociais
}

\author{
Appointments and Meanings of Male \\ Homosexuality: An Essay on Homophobia from \\ the Perspective of the Theory of Social \\ Representations
}

\author{
Augusto César Cardoso Mendes ${ }^{1}$ \\ Luiz Paulo Ribeiro ${ }^{2}$
}

DOI: 10.19177/memorare.v8e12021247-264

\begin{abstract}
Resumo: A violência homofóbica tem se caracterizado como um problema social. Essa forma de violência pode se caracterizar na forma de xingamentos, nomeações ofensivas e que expressem desqualificação. Neste estudo, nos debruçamos sobre as nomeações que homossexuais masculinos (homens gays) recebem socialmente, com ênfase na nomeação "viado". Para esta análise, acionamos a Teoria das Representações Sociais para compreender a aplicação dessas expressões frente as questões históricas, nas quais é comum encontrar fatos que dizem respeito a desvalorização e violência para com os sujeitos não heteroafetivos e não cisgêneros. A construção teórica do texto foi baseada em uma pesquisa bibliográfica, que teve como finalidade reunir outras produções científicas que já tangenciaram a temática. 0 trabalho evidenciou que algumas representações sociais sobre a homossexualidade podem favorecer a homofobia.
\end{abstract}

Palavras-chave: Homossexualidade. Representações Sociais. Homofobia. Violência.

\begin{abstract}
Homophobic violence has been characterized as a social problem. This form of violence can be characterized in the form of insults, offensive terminologies and which express disqualification. In this study, we look at the nominations that male homosexuals (gay men) receive socially, with an emphasis on the nomination "viado". For this analysis, we used the Theory of Social Representations to understand the application of these expressions in the face of historical issues, in which, it is common to find facts that say about devaluation and violence towards non-hetero-affective people and people that are non-cisgender. The theoretical construction of the text was based on a bibliographic research that aimed to gather other scientific productions that have already touched on the theme. The work showed that some social representations about homosexuality can favor homophobia.

Keywords: Homosexuality. Social Representations. Homophobia. Violence.
\end{abstract}

\footnotetext{
1 Psicólogo, mestrando em Educação: conhecimento e inclusão social (UFMG). E-mail: gutocm8@gmail.com.

2 Psicólogo, mestre em Promoção de saúde e prevenção da violência, doutor em Educação. Professor de Psicologia Social da Educação na Faculdade de Educação da UFMG. E-mail: luizribeiro@live.com.
} 


\section{Introdução}

As discussões sobre a violência e o preconceito para com a população de homens gays têm ficado cada vez mais aparentes, tanto nas redes sociais quanto nas publicações científicas (GAVAZZONI; SOUSA, 2018). No Brasil, pode-se dizer que a temática da homofobia ganhou mais visibilidade a partir do julgamento da Ação Direta de Inconstitucionalidade (ADI) que tipificou como crime de racismo, também, as condutas homotransfóbicas. Este discurso ganhou espaço social e trouxe à tona a própria história do movimento gay no Brasil e do extenso rastro de violência contra as pessoas não heterossexuais e não cisgêneras no país.

Neste ensaio temos como foco a violência contra homens gays: a violência homofóbica (SILVA et al., 2020) que pode aparecer de diferentes formas. Neves, Batista e Levandoski (2020), apontam que ela pode ser caracterizada como, desde um medo descomedido e sem razão de homossexuais, até ações e discursos que visem oprimir premeditadamente, discriminar, assediar ou violentar fisicamente ou verbalmente pessoas homossexuais.

Como um medo irracional da homossexualidade/homossexuais, incluindo, opressão premeditada, discriminação, assédio moral e violência física; também se refere a atitudes e comportamentos negativos de medo ou de ódio contra gays, lésbicas e transgêneros. (NEVES; BATISTA;

LEVANDOSKI, 2020, p. 2)

Como indicado, essa forma de violência pode aparecer não apenas como algo físico-visível contra os sujeitos gays, mas também como formas de se dirigir a estes sujeitos, com xingamentos ou outras expressões que podem ter seu sentido modificado para humilhar, subalternizar e, até mesmo, negar para essas pessoas o acesso à serviços e políticas públicas. Assim sendo, este ensaio tem como objetivo resgatar algumas das nomeações e significações dados a homossexuais masculinos analisando possíveis representações sociais que dão/ têm origem em preconceitos e na homofobia.

A utilização da Teoria das Representações Sociais (MOSCOVICI, 1978) se deu por que há indícios de que a forma que certos sujeitos são vistos e interpretados impacta, diretamente, nas formas como eles se veem, se sentem e como comportam, o que pode ser entendido como uma relação direta entre as $\mathrm{RS}^{3}$ e os processos identitários (RIBEIRO; ROCHA, 2019).

Cabe ressaltar que a Teoria das Representações Sociais nasceu na década de 1960, na França, por Serge Moscovici. Este psicólogo social, em sua tese de doutoramento, preocupou-se em analisar como a Psicanálise, em dispersão na França naquela época, chegava e era apreendida por diferentes grupos, que a liam e aderiam aos seus aspectos a partir de suas próprias lentes. Para tanto, Moscovici (2012) trabalhou com os processos de objetivação e ancoragem que dizem da passagem de algo que é considerado não-familiar (estranho) em familiar (conhecido). Sabe-se, então, que quando se fala em representações sociais, fala-se sobre as diferentes formas dos grupos pensarem,

\footnotetext{
3 Durante o texto, utilizaremos a sigla "RS" em correspondência ao termo "Representações Sociais"
} 
sentirem e agirem frente a diferentes objetos (que podem ser desde propriamente objetos, até mesmo pessoas, identidades e países).

Moscovici (1978) trabalhou com a ideia de que "a opinião é, por um lado, uma fórmula socialmente valorizada a que um indivíduo adere; e, por outro lado, uma tomada de posição sobre um problema controvertido da sociedade" (MOSCOVICI, 1978, p. 46). Adiante, Alves (2000) esmiúça, ainda mais, essa proposta ao afirmar que as representações sociais vão além de meras opiniões formadas sobre algo. Ao contrário, são concepções coletivas, estruturadas por meio de uma linguagem e dinâmica características, as quais determinam, baseadas em conceitos e valores específicos, que serão partilhadas pelos coletivos, ditando, por consequência disso, o que é permitido e admissível.

Percebe-se, portanto, que, para Moscovici (1978), a representação social é um mecanismo utilizado pelo sujeito para que ele dê conta de balizar sua percepção sobre o mundo, desenvolvendo, a partir de saberes propostos na sua vivência social as explicações necessárias para entender a atribuição de sentido e significado às coisas. "Em poucas palavras, a representação social é uma modalidade de conhecimento particular que tem por função a elaboração de comportamentos e a comunicação entre indivíduos" (MOSCOVICI, 1978, p. 26).

Por sua vez, Jodelet (2001) aponta que as representações sociais também são orientações à prática, ou seja, indicações sobre como se posicionar frente a um determinado objeto, uma vez que a ação é, em alguma medida, operacionalizada pela forma de pensar e sentir o próprio objeto socialmente partilhado. Neste caminho, há a hipótese de que o sujeito se insere em grupos que cultivam posicionamentos, condutas, valores e atuações em comum aos seus.

No caso específico deste texto nos debruçamos sobre nomeações que recebem popularmente e socialmente os sujeitos que se assumem/consideram/performam a homossexualidade masculina, ou seja, homens gays. Entendemos que os demais sujeitos, sujeitas e sujeites LGBTQIA+ também são nomeados com formas pejorativas que se tornaram comuns socialmente, embora expressem violência. No caso deste estudo, o foco foi aquelas recebidas por homens gays, entendendo ser necessário abrir espaço neste campo para outras investiduras a devir.

Deste modo, ao buscar balizamento dessa discussão por meio da teoria supramencionada, espera-se explicar como, por exemplo, a palavra "viado" assume sentidos, significados e simbolismos distintos de acordo com as representações sociais empregadas pelos grupos que a utilizam.

Partimos do pressuposto de que os significados precedentes às palavras fazem parte da identidade do grupo que a utiliza, visto que ele é regulado por meio das suas próprias representações sociais, isto é, o grupo se mantém atendendo às "meta-informações" preservadas e estimuladas por seus componentes (WAGNER, 1998). Dessa forma, entendemos que um indivíduo heterossexual que faz parte de um grupo formado por representações sociais baseadas na heteronormatividade poderá utilizar nomeações como "viado" quando estiver se referindo a um homem homossexual com a intenção de ridicularizá-lo, ofendê-lo e 
vexá-lo. Isto porque pode ser que a identidade partilhada pelo seu grupo está associada às RS que consideram a homossexualidade uma expressão da sexualidade que possui conteúdos identitários opostos aos seus, ou seja, é considerada "errada" por ser diferente do padrão hegemônico heteronormativo.

Entretanto, o mesmo coletivo de homens heterossexuais, todavia, pode utilizar esta palavra com outra intenção, desta vez, completamente oposta à que foi mencionada: um homem heterossexual pode chamar de "viado" outro que considera semelhante a ele sem, necessariamente, empregar sentido pejorativo à palavra. Desta vez, o vocábulo assume um outro significado, como uma gíria, visto que o grupo entende, majoritariamente, que mesmo que os integrantes dele utilizem essa palavra como vocativo, a identidade presente nele não será deturpada ou alterada porquanto a intenção precedente à palavra é diferente, não é depreciativa, mas amistosa, uma vez que nesse contexto, esse termo é ancorado em outras representações sociais.

Diferentemente, ainda, "viado" pode ser uma expressão utilizada por pessoas que compõem grupos gays e LGBTQIA+ com a finalidade de se reconhecerem entre si como indivíduos que integram o mesmo coletivo e estão unidos por uma identidade que é partilhada, formalmente, por todos. À vista disso, entende-se que, neste caso, esse grupo possui outras RS para operacionalizar suas práticas, valores e ideias, as quais são, terminantemente, diferentes das representações sociais que sustentam o pejorativismo da palavra "viado" atingindo neste último caso, inclusive, um uso da nomeação como resistência política.

Foi, justamente, essa pluralidade de significações ancoradas em diferentes elementos que representam a nomeação em questão que nos fez produzir esse texto. Isso por que as inquietudes e questões acerca de como um mesmo termo pode assumir sentidos tão opostos e absorver intenções distintas suscitaram o nosso trabalho e investigação, com vistas em buscar explicações na Teoria das Representações Sociais (MOSCOVICI,1978) para compreender como nomeações, como a palavra "viado", sofreram alterações de sentido, intenção e significações.

Ademais, entendemos a necessidade de contribuir para o fomento de discussões sobre o enfrentamento à violência e à homofobia. Isso por que, assumir um posicionamento de apoio à liberdade das múltiplas expressões da sexualidade, o qual vá ao encontro dos pressupostos da liberdade sexual, preconizados pela Declaração Universal dos Direitos Humanos (ONU,1948) é um compromisso, além de ético, humano. Assim como, desenvolver contribuições acadêmicas sobre a temática, em um momento em que o Brasil enfrenta iminentes ameaças fascistas e fundamentalistas é um ato de resistência à intolerância e preservação dos direitos conquistados pela comunidade LGBTQIA+, em especial pelos sujeitos gays.

De igual modo, podemos julgar que ao discutirmos a homofobia, trazendo um enfoque analítico que propõe investigar terminologias que são, comumente, utilizadas por diferentes grupos sociais, com sentidos e intenções específicas, estamos contribuindo para o debate e a crítica à violência homotransfóbica. Entendemos que todo os sujeitos que se assumem/nomeiam/identificam como LGBTQIA+ podem ter relatos nos

Memorare, Tubarão, v. 8, n. 1, jan./jun. 2021. ISSN: 2358-0593 
quais as nomeações são formas de expressar a violência, porém neste texto focalizamos aquelas recebidas por homens gays, mesmo entendendo que no universo das pessoas não cisheteronormativas isso seja apenas uma 'gota no oceano'.

\section{Da normalidade à violência homofóbica}

Com efeito, torna-se possível compreender que a violência homofóbica (SILVA et al., 2020) ocorre porque encontra, em algumas representações sociais sobre a homossexualidade, respaldo para considerar que ela é inferior à heterossexualidade e, por isso, é mister que ela seja subjugada para que ocorra a manutenção da hegemonia heteronormativa.

A ideia de que a homossexualidade é uma orientação sexual rebaixada em comparação à heterossexualidade é abordada por Foucault (1984) quando o autor afirma que o modelo heterossexual de relacionamento é reputado pelas civilizações como um padrão aceitável à moralidade. 0 teórico retoma à Grécia Antiga para explicar que, naquele período, era comum que homens se relacionassem com rapazes mais novos, a fim de que os mais jovens servissem de objetos de prazer para os mais velhos. Foucault (1984) ressalta que essa relação deveria ser operacionalizada sem que houvesse um envolvimento cuja intenção trespassasse o propósito de gerar prazer para o homem adulto. Aponta, ainda, que o homem detinha um papel fixo em relação a sua conduta sexual, ou seja, ele deveria ser sempre um sujeito dominante, cuja atuação precisava estar de acordo com a virilidade, masculinidade e a superioridade. Ao assumir uma posição diferente desta, instantaneamente, considerava-se que aquele homem estaria destoando do padrão de masculinidade imposto, o que lhe atribuía um local de inferioridade, comparado ao das mulheres, haja vista que de acordo com o autor, para algumas civilizações, elas, desempenhavam um papel ínfero (tanto sexual, quanto social) em relação ao homem.

0 rapaz que se sujeitasse às relações com homens mais velhos poderia fazê-lo com a justificativa de ainda não ter alcançado um status de virilidade e, por isso seria legítimo que, naquele momento de sua vida, ele se tornasse objeto de prazer para homens adultos. Após alcançar a maturidade e as condições de "exercer poderes e responsabilidades” (FOUCAULT, 1984, p. 215), ele não deveria mais relacionar-se com outros homens a fim de lhes proporcionar prazer. Agora, o garoto, recém tornado homem, teria de desempenhar o papel daqueles com os quais ele se relacionava anteriormente, isto é, a função de dominador, "macho" e viril. Contudo, mesmo após ter alcançado a maturidade referida, se o homem continuasse assumindo uma posição de submissão, permitindo ser dominado, inclusive durante o ato sexual (ser penetrado), ou seja, perpetuasse sua experiência sexual homoafetiva da juventude para a fase adulta, ele seria desqualificado e reconhecido como inferior (FOUCAULT, 1984).

0 ato de inferiorizar o rapaz que se propusesse continuar experienciando relações sexuais com outro homem, sem a justificativa de estar servindo com objetivo de prazer para ele, denotava que este primeiro havia decaído "de sua própria natureza" (p. 217), uma vez que a prática homossexual desempenhada para além da ressalva que 
permitia jovens serem objetos de prazer para homens mais velhos era entendida como algo não natural (FOUCAULT, 1984).

Outros autores, também, contribuíram com as discussões a respeito da homossexualidade ao longo da história, com ênfase nas explicações sobre os motivos que propiciaram a construção de sentidos negativos e supressores que rondam essa temática. Spencer (1999) cita que a união entre a Igreja e o Estado, na Europa Medieval propiciou a sacralização da sexualidade, o que a tornava algo que deveria ser exercido em alinhamento com as recomendações eclesiásticas. Diante disso, convencionou-se estabelecer a heterossexualidade como o ideal a ser seguido, uma vez que somente a relação sexual feita por pessoas de sexos opostos poderia levar a reprodução humana. 0 autor cita, ainda, que justamente, por não se relacionarem sexualmente com o intuito de reproduzirem, nessa época, os homossexuais foram igualados a malfeitores, traidores e hereges. Peters (2017) aponta que a homossexualidade tem sido reconhecida como uma prática desviante do "padrão natural" estabelecido pela sociedade, ao longo da história das civilizações. Isto porque, segundo o autor, as religiões, mais precisamente, as que têm a Bíblia Sagrada como orientadora prática da fé dos fiéis pregam que a homossexualidade é uma abominação, o que, propositalmente, influenciou na forma que os sujeitos entendem a homossexualidade.

Toniette (2006) salienta que a homoafetividade sempre existiu na humanidade, estando presente em diferentes épocas e períodos históricos. Contudo, o autor aponta que a relação afetivo-sexual entre pessoas do mesmo sexo nem sempre foi considerada como algo "errado" ou "doentio". Para o escritor, a partir do século XIX, data em que o modelo higienista começou a ganhar força, a figura da pessoa homossexual passou a ser construída dentro de um contexto médicolegal, psiquiátrico, sexológico e higienista, a fim de contrastar com o padrão de masculinidade da época. Outra discussão apontada pelo autor diz respeito à criação de uma imagem da homossexualidade que estivesse, naturalmente, atrelada à promiscuidade ou a algo que não estivesse em acordo com os padrões da moralidade. Seus escritos afirmam que a sociedade burguesa daquela época valorizava, em demasia, a preservação do pudor e da imagem das famílias. Diante disso, a homossexualidade que era vista como uma modalidade estranha e não natural da sexualidade, frequentemente, era associada à pedofilia e à transmissão de doenças, o que favorecia a ideia de que ela era uma ameaça ao modelo de moralidade pregado na época.

Entretanto, segundo Dieter (2012) a partir da segunda metade do século XX foi iniciada uma pequena mudança paradigmática sobre a temática LGBT, em especial, em relação à homofobia. De acordo com a autora, após a segunda metade do século XX, as famílias foram deixando de ser influenciadas, somente, pelas tendências machistas que estimulavam determinados comportamentos e condutas das pessoas. Sendo assim, os sujeitos começaram a valorizar o respeito e a dignidade de cada membro do grupo familiar, o que permitia o acolhimento de pessoas que, porventura, fossem homossexuais ao seio da família. Diante disso, tanto as manifestações da sexualidade de cada pessoa que compunha o lar começaram a ser respeitadas, quanto às diferentes 
configurações de famílias, também, começaram a ser observadas e reconhecidas. A autora, também, afirma que no período pós-moderno (em que a sociedade se encontra, atualmente) atitudes e condutas contrárias à homofobia têm sido cultivadas pelas pessoas. Movimentos que prezam pela liberdade da sexualidade têm ganhado espaço, com a finalidade de incentivarem a vivência e a naturalização das mais diversas expressões da sexualidade humana.

O estigma e a subalternização da pessoa homossexual foi algo tão acentuado e marcante que, a partir da década de 1980, a comunidade gay começou a ser associada, diretamente, a ideia de que ela, naturalmente, estava vinculada a transmissão da AIDS, considerada inicialmente como "câncer gay". Como afirma Terto (2002), nessa época, houve uma tão intensa correlação entre a doença e a comunidade gay que até os cientistas consideravam essa moléstia como algo específico das pessoas homossexuais, chegando alguns pesquisadores da época a nomearem a doença como GRID (Gay Related Immunedeficiency Disease). Contudo, mesmo após comprovado que o vírus não é transmitido somente por/para pessoas homossexuais, os sujeitos que compõem a comunidade gay ainda sofrem preconceito por causa dessa associação, uma vez que são vistos como veículos de transmissão da doença, o que pode, ainda hoje, acabar impulsionando, ainda mais, a homofobia.

Ao congregar as contribuições históricas apresentadas, tencionouse relatar como a sociedade construiu ideais do que é ser homem e, por consequência, como as pessoas não heterossexuais não se enquadram neles. Entendemos que, de alguma forma, essas construções históricas acabaram por legitimar a violência homofóbica. Por estarem ancoradas em questões sociais somadas a cada período histórico, as representações sociais sobre a homossexualidade, de alguma forma, foram orientadas pela ideia de que a heterossexualidade é uma orientação sexual natural e, por isso, qualquer outra diferente dela deve ser reprimida.

Contudo, a comunidade LGBTQI+ tem assumido determinado protagonismo no que se refere ao enfrentamento direto a estas ideias e posicionamentos que, por muitos anos, subalternizaram as pessoas homossexuais. Como resultado de décadas de lutas e reivindicações por direitos, respeito e progresso para esse coletivo, algumas mudanças sociais que refletem um possível avanço das pautas discutidas por esses grupos foram consolidadas. A exemplo disso temos a despatologização da homossexualidade, registrada em 1993, após a publicação da CID 10, que colocou fim à hipótese de que a homossexualidade seria uma doença; e a criação da Associação Brasileira de Lésbicas, Gays, Bissexuais, Travestis e Transexuais (ABGLT), também em 1993, responsável pelo encaminhamento de discussões sobre saúde, violência e infraestrutura dos grupos gays no país, que foram marcos significativos em relação aos direitos humanos da comunidade LGBT no Brasil (REIS, 2012).

No país, em específico, os progressos relacionados às políticas públicas para a população LGBT ganharam maior espaço a partir do lançamento do programa "Brasil sem homofobia" em 2004, construído em articulação entre a sociedade civil e o governo. Suas propostas 
contavam com 53 ações, articuladas por 18 ministérios, visando o combate à violência e o enfrentamento à discriminação da pessoa homossexual, bem como o estímulo de sua cidadania (REIS, 2012).

Dieter (2012) cita que a sociedade começou a ser estimulada por movimentos libertários, os quais propuseram algumas iniciativas, como a festividade das paradas do orgulho gay - hoje como paradas LGBTQIA+ - as quais buscam naturalizar as homossexualidades. Movimentos como esse têm como finalidade demonstrar que as pessoas homossexuais devem ser reconhecidas como sujeitos que, naturalmente, são como são, não por desvios morais ou patologias, mas porque, simplesmente, compõem uma outra categoria (também, natural e normal) dentro das mais variadas esferas relacionadas às orientações e expressões da sexualidade humana.

0 autor cita, ainda, o avanço em relação ao esclarecimento das nomenclaturas "opção sexual" e "orientação sexual". Para Dieter (2012), tem se entendido que não é viável dizer "opção sexual", mas sim, "orientação sexual", uma vez que a pessoa homossexual não escolhe se tornar gay ou hétero. Ao contrário, ela, naturalmente, tem seu desejo sexual direcionado às pessoas do mesmo sexo, não tendo o domínio de escolher ou selecionar por quem quer ter interesse ou aptidão sexual.

De acordo com Verbicaro (2019), iniciativas nos campos jurídico e político têm se configurado como aliadas contra a discriminação da pessoa homossexual. 0 escritor cita, como exemplo, o reconhecimento das uniões entre pessoas do mesmo sexo pelo Supremo Tribunal Federal, em 2011. Entretanto, o autor aponta que é necessário mais do que apenas o reconhecimento do STF à união entre casais gays para que a homofobia seja enfrentada, uma vez que a intolerância e o desrespeito estão enraizados nas condutas dos brasileiros. É importante, ainda, citarmos a conquista da adoção de crianças por parte de casais homossexuais, sendo que essa modalidade de adoção (relativamente nova) tornou-se legítima após o Poder Judiciário ter acesso a diferentes estudos e pareceres científicos que confirmaram que a orientação sexual dos adotantes, não necessariamente, influirá na orientação sexual do adotado. Segundo Peters (2017), as questões referentes à homossexualidade têm sido respaldadas pelo conceito de cidadania, de modo que o coletivo LGBTQI+ possa sentir-se incluso em uma sociedade que é, tipicamente, heteronormativa.

Mesmo com tantos avanços, ainda hoje é possível que alguns heterossexuais - que possuem condutas e valores que os unem por uma identidade grupal, a qual exerce influência direta na identidade individual de cada membro - sejam estimulados por determinadas representações sociais sobre a homossexualidade. Essas representações dotadas de conteúdos pejorativos, preconceituosos e subalternizantes, podem os influenciar nas formas de pensar, sentir e agir e, de alguma forma, serem sustentáculo para ancorar suas percepções (homofóbicas) a respeito da "não-naturalidade" da homossexualidade. Em outras palavras, diz-se que, nesse caso, a homofobia exercida por esse coletivo de heterossexuais é sustentada por uma errônea concepção, construída historicamente, de que o único modelo correto de orientação sexual é a heterossexualidade e, por isso, tudo o que contrastar com ele deverá ser combatido. 
Neste âmbito, é interessante pensar que os processos identitários são mecanismos importantes para a elaboração da autopercepção das pessoas e para a regulação dos grupos em que elas estão inseridas. Segundo Carmo e Resende (2018), ao identificar o que faz parte do sujeito e o que faz parte do grupo, ao qual ele pertence, é possível que sejam feitas comparações entre o que o caracteriza e o que está distante dele, isto é, o que tem sido construído em sua identidade e o que é alheio a ela. Diante disso, pode-se pensar o quanto as representações sociais sobre a homossexualidade têm influenciado na construção da identidade das pessoas homossexuais ao longo da história.

Carmo e Resende (2018) apontam que as representações possuem um caráter comunicativo, o qual é utilizado como veículo para compartilhar, dialeticamente, elementos específicos entre o indivíduo e o grupo em que ele está presente. A pesquisa feita pelos autores supramencionados demonstrou que a identidade das pessoas homossexuais é, com efeito, construída através de suas compreensões sociais sobre a sexualidade. De acordo com eles, para o homossexual, a sua compreensão social sobre a homossexualidade é balizada, diretamente, pelas representações sociais sobre a homossexualidade. Essas representações regulam o modo como um sujeito homossexual constrói sua identidade e orienta suas práticas sociais em relação a sua própria orientação sexual. Logo, as representações sociais partilhadas por homossexuais exercem influência direta na forma como o sujeito gay se vê, se considera e se comporta. Carmo e Resende (2018) apontaram em seus estudos, inclusive, que o modo pelo qual a pessoa homossexual relaciona-se com sua sexualidade está, proporcionalmente, ligado ao histórico de punições sofridas por ele em razão da sua orientação sexual.

Diante disso, pode-se entender que, ao longo dos anos, as representações sociais sobre a homossexualidade serviram como forma de orientar as práticas das pessoas homossexuais acerca de suas próprias sexualidades. 0 que se sabia a respeito do que significava "ser gay" influenciava, diretamente, na formação da identidade da pessoa que se identificava como tal. Assim sendo, todo o histórico de subalternização e preconceito, observado desde os períodos citados, como a Grécia Antiga e a Idade Média, servia como orientador para a construção da identidade das pessoas homossexuais. Carmo e Resende (2018, p.18) ratificam essa ideia quando afirmam que o modo como os sujeitos homossexuais representam a homossexualidade está ligado a forma como eles "assimilaram as RS que existiam em suas comunidades e com o conteúdo dessas RS, baseadas muitas vezes em estereótipos e preconceitos."

Não diferente, hodiernamente, não são raros os relatos de que quando um homem revela sua homossexualidade - sair do armário, coming-out - ele pode se sentir como inferior. A inferioridade atribuída a ele está ligada, diretamente, à ideia de que a identidade homossexual que foi formada pelas representações sociais sobre a homossexualidade é, indubitavelmente, subalterna à heterossexualidade. Figueiró (2009) afirma que no campo das discussões sobre a sexualidade, a homossexualidade é reconhecida como uma "classe" naturalmente inferior por ser colocada como uma tendência desviante aos padrões

Memorare, Tubarão, v. 8, n. 1, jan./jun. 2021. ISSN: 2358-0593 
estipulados por quem determina qual é o modelo de sexualidade aceitável, isto é, a cultura heteronormativa patriarcal. A autora evidencia que a palavra 'viado' está presente, cotidianamente, na linguagem das pessoas que acreditam que orientações sexuais diferentes da heterossexualidade são, seguramente, inferiores.

\section{3 'Viado': sentidos e significados}

Jesus (2020) afirma que dentre os vários significados do termo inglês queer ${ }^{4}$ aparece a palavra 'viado', entretanto, o autor aponta que o vocábulo estrangeiro, ao ser traduzido para a Língua Portuguesa não consegue expressar, em sua totalidade, o peso pejorativo presente nela. Nascimento (2020) utiliza a contribuição de Zamboni (2016) quando o autor discute a homossexualidade dentro dos presídios para dizer que a palavra 'viado' foi um dos termos utilizados pelos detentos, em outro momento, para caracterizar um indivíduo que apresentasse um comportamento destoante ao padrão heteronormativo, mas que, ao longo do tempo, foi ressignificado pelos próprios detentos homossexuais que atribuíram a essa expressão um outro significado, desta vez, com a finalidade deles se reconhecerem enquanto grupo identitário. Para Rosa, Souza e Borges (2020), a palavra pode ser entendida como uma expressão que rotula, classifica e nomeia, preconceituosamente, o estigma contra os homossexuais.

Não longe desta significação, Lau e Ferreira (2015) salientam que o estereótipo da pessoa homossexual é facilmente assimilado a delicadeza e a suavidade do veado "Bambi"5. Assim, o comportamento do homossexual masculino está, diretamente, vinculado à imagem desse personagem porque a suposta forma delicada do homem gay interagir, andar e expressar propicia a vinculação de sua imagem ao animal presente no filme. Essa associação atribui e reforça ao homem gay uma imagem de frágil, delicado e sensível, haja vista que a personagem possui essas mesmas características e, ao vincular Bambi ao homem gay, tais particularidades lhe são atribuídas e representadas.

Cittadin e Lino (2018) trazem contribuições importantes acerca de como se deu a atribuição de um sentido aviltante a essa palavra. Logo no início, os autores salientam que a grafia da palavra está em contradição à grafia empregada pelo dicionário Houaiss (2009), uma vez que, baseado nele, a dupla de autores afirma que "a palavra que corretamente representa o homem homossexual seria 'veado' ao invés de 'viado'”. (CITADDIN \& LINO, 2018, p. 4). Uma contribuição importante trazida por eles é a explicação sobre a associação da palavra 'viado' à figura do homossexual masculino. Os escritores trabalham com duas hipóteses para tentar explicar a origem do termo pejorativo. Primeiramente, baseados no artigo "Como é a vida sexual dos veados?" escrito pelo Zoólogo Ricardo Barbieri (2010), eles encontraram informações que apontam que o comportamento natural dos veados os caracteriza como seres "delicados", "suaves" e "tímidos" e, diante disso, convencionou-se associar tais características ao homem homossexual,

\footnotetext{
${ }^{4}$ A Teoria Queer possui uma série de significações e é discutida por alguns autores com enfoques e conceitos específicos. No entanto, ao citá-la, buscamos ancorá-la à imagem de sujeitos que não se identificam ou não correspondem a um padrão cisheteronormativo.

5 Personagem representado por um animal veado que foi desenvolvido pela Walt Disney, em 1942.
} 
visto que, supostamente, ele as teria. Outra explicação trazida por eles é baseada no "Dicionário Brasileiro de Insultos" escrito por Aranha (2002), o qual afirma que:

Mamífero da família dos cervídeos quase sempre tímido e veloz. Vive em bandos. Usa-se no Brasil, com muita frequência para insultar a vítima, identificando-a como homossexual masculino. Dizem que nos tempos do Império, em praças, provavelmente cariocas, rapazes reuniam-se alegremente, formando bando de afinidades, para, entre outros objetivos, dar atendimento a clientes ricos em busca de aventuras sexuais. Quando a polícia, que nunca foi amiga dos veados, aproximava-se para coibir a caça, eles saíam correndo, aos saltos, como fazem os cervídeos. Disso resultou a criação do alcunha [sic] que se fixou como um dos mais populares do Brasil. (ARANHA, 2002, p. 352)

Ladeira (2018), levanta outra discussão em se tratando do significado da palavra referida, desta vez, não ao que tange à atribuição do sentido a ela, mas sim, no que se refere à distinção entre os significados das palavras 'gay' e 'viado'. 0 autor aponta que as duas expressões nomeiam um homem que se relaciona com pessoas do mesmo sexo, contudo, ele descreve que existe uma diferença de sentidos presente nas duas palavras. Isto porque, apesar de ambas representarem um homem não heterossexual, existe uma distinção entre elas, tal diferença é atribuída à forma como o homem homossexual se comporta diante da sociedade. De acordo com o escritor: "o gay é aquele indivíduo que embora tenha a sua orientação sexual categorizada como homossexual, procura ser discreto e goza de um certo respeito por parte da sociedade, pautado na sua 'discrição' em relação a sua orientação sexual” (LADEIRA, 2018, p.2). Já a palavra 'viado' caracteriza

aquele que dá certos indícios de sua orientação sexual e por essa razão recebe da sociedade uma certa hostilização. Ele geralmente não é bem visto socialmente, por expor sua orientação sexual, que aliás, segundo o senso comum é entendido como opção sexual. É aquele que, segundo a própria sociedade, não detém o respeito social por não se comportar conforme o esperado pelas regras patriarcais impostas pela mesma. É aquele que desafia as normas, se recusa a docilizar o seu corpo e sua conduta, troca beijos e carinhos em público, anda de mãos dadas, em linhas gerais, é aquele que "saiu do armário" (LADEIRA, 2018, p.2).

Percebe-se que o sentido pejorativo presente dentro da expressão 'viado' é preenchido por uma série de sentidos que inferiorizam o homossexual masculino. Nota-se que ao empregar uma carga difamatória à palavra citada, tenciona-se caracterizar sujeitos que estão em desacordo com os ideais impostos pela heteronormatividade. Esses referenciais hegemônicos prezam que qualquer comportamento que seja diferente de uma conduta "masculinizante", "forte", "brava" e "destemida" representa uma orientação sexual "decaída". Em outras palavras, o padrão cristalizado do modelo de homem imposto pelo patriarcado impõe que exista uma conduta única e específica, a qual sugere que caso um sujeito apresente desvios - ainda que ínfimos desse referencial, ele não mais representará uma preeminente masculinidade, mas exercerá uma masculinidade "rebaixada".

Para Butler (1993), propor uma conexão unilateral, em que a sexualidade e o gênero não consigam ser desassociados um do outro é

Memorare, Tubarão, v. 8, n. 1, jan./jun. 2021. ISSN: 2358-0593 
um intento ao fortalecimento da homofobia. De acordo com a autora, o homofóbico trabalha com a perspectiva da associação do sexo biológico ao gênero que corresponde, exatamente, ao sexo da pessoa, ou seja, a mulher se enquadra no gênero feminino e o homem no gênero masculino. Dessa forma, o agressor parte da premissa de que o homem gay possui determinadas condutas sexuais e sociais que são, geralmente, exercidas pela mulher e a mulher gay possui determinadas condutas sexuais e sociais que, em geral, são exercidas pelo homem e, por isso, ambos possuem algum erro ou desacerto. Butler acentua que a homofobia está instalada, justamente, nesse pensamento, uma vez que para o homofóbico depreciar o homem gay, o agressor precisa, automaticamente, desqualificar o feminino, pois ele tem de representar, dicotomicamente, o feminino como sendo o negativo, o errado, o avesso ao homem e o masculino como o certo. Para melhor elucidar, afirma-se que o preconceituoso associa o feminino a um fracasso em detrimento ao masculino.

Os estudos sobre as masculinidades têm contribuído com as discussões a respeito do papel desempenhado pelo homem nos sistemas que estruturam e hierarquizam a sociedade. De acordo com Saraiva, Santos e Pereira (2019), entende-se que a heteronormatividade é conceituada como "norma" padrão pela qual a sexualidade deve ser regulada. Para os autores, tanto a heteronormatividade quanto a masculinidade foram socialmente construídas para diferenciar e demarcar o binarismo presente entre masculino e feminino. Assim, a masculinidade além de ser uma modalidade cultural estimulada em diferentes organizações, também, é um produto cultural valorizado, não somente por homens, mas, de igual modo, por algumas mulheres.

Neto, Firmino e Paulino (2019) afirmam que a masculinidade é um produto herdado do modelo de família adotado pela burguesia. De acordo com seus escritos, o homem, além de ser responsável pela renda, era encarregado de zelar pela família e pelas tradições. Tomando como exemplo, vê-se que na Idade Média, a imagem do pai como provedor e da mãe como responsável pelo afeto e criação dos filhos auxiliou na conceituação do que significa "ser homem".

Dantas (1997), aponta que a masculinidade é uma construção social que acontece nos seguintes níveis: relacional, contextual e histórico. Para o autor (1997, p. 42), o eixo básico das pesquisas que estudam nesse campo é caracterizado por "demarcar como se situam os homens - homossexuais ou heterossexuais - frente às transformações culturais impostas pelos movimentos feminista e gay".

A exemplo disso, o estudo de Almeida (2018) reuniu apontamentos que ilustraram a variedade das identidades masculinas em uma aldeia Alentejana (região do centro-sul de Portugal), no qual afirma que o corte que distingue e afasta a equidade de gênero entre as mulheres e os homens é o patriarcado, já a divisão que retira um homem do seu local análogo (em se tratando do gênero pelo qual ele se identifica) é a polarização entre uma masculinidade que é hegemônica e outra que se torna inferior a ela (ALMEIDA, 2018, p. 97).

Diante do que foi trazido, até aqui, é possível notar que a homofobia atua, em particular, onde há a oposição aos padrões , haja vista que qualquer vivência estranha ao "modelo de homem" que é 
proposto pela heteronormatividade acarretará na ridicularização do sujeito por meio do "feminino negativo", isto é, através de compará-lo com algo inerente ao feminino e, consequentemente, evidenciar que esse "algo" é, naturalmente, inferior ou ruim.

Percebe-se, então, o quanto a homofobia é uma questão que além de ridicularizar o homem gay, possui uma parcela depreciativa à mulher, haja vista que as atribuições que foram construídas socialmente sobre o feminino ao serem incorporadas por um homem gay o fazem ser classificado como "fora do padrão", "estranho" e, por isso, ele é taxado, automaticamente, como "inferior". É, consequentemente, possível indicar que as representações sociais sobre a homofobia propiciam o entendimento de que a palavra 'viado' abarca uma noção depreciativa específica sobre o "feminino negativo", uma vez que a intenção homofóbica presente na palavra está associada a atribuição de um desprezo, repulsa e desqualificação por algo que, pertence (após ser formalizado por meio de uma construção social e histórica) à mulher. Então, após tomar para si esse algo que é "naturalmente feminino", o homossexual é colocado como inferior perante a classe heterossexual, dado que ela entende que ele se desviou de uma conduta superior (ser homem) e agora encontra-se "decaído", ocupando um lugar ao lado da mulher, que por ser vista como inferior - numa lógica patriarcal/heteronormativa - permite entender que o homem homossexual, também, o é.

Para explicar os processos que formam as representações sociais sobre a homofobia será utilizada a contribuição de Moscovici (2012) quando o autor conceitua dois princípios teóricos fundantes de sua Teoria: a ancoragem e a objetivação. Explicando os dois conceitos, diz-se que a ancoragem é responsável pela caracterização e nomeação de algo ou alguém. Para o teórico, a sua atuação se dá a partir da transformação de algo estranho e, até mesmo, incômodo em algo comum, conhecido e próximo. Chamon (2006) cita que a ancoragem tem como finalidade formar na cognição do sujeito, a partir do objeto representado, significados e interpretações que unam aquele objeto (até então, estranho) a conteúdos e elementos familiares. Já a objetivação é um processo que permite tornar concreto, compreensível aquilo que, até então, era abstrato. Segundo Moscovici (2015, p. 71):

a objetivação une uma ideia de não familiaridade com a realidade, tornase a verdadeira essência da realidade. Percebida primeiramente como um universo puramente intelectual e remoto, a objetivação aparece, então, diante de nossos olhos, física e acessível.

Partindo desse pressuposto, entende-se que esses dois processos são ferramentas importantes para explicar a dualidade de sentidos que a palavra 'viado' adquire em detrimento da intenção empregada a ela. Como já afirmado, essa expressão pode conter tanto uma carga depreciativa - quando utilizada para depreciar pessoas não heterossexuais -, quanto não depreciativa - quando pessoas gays a utilizam como marco de identidade ou quando pessoas não heterossexuais a utilizam como gíria.

Tendo como base a ideia de que as representações sociais são formadas por meio dos processos de ancoragem e objetivação, pode-se refletir que esses dois processos colaboram com a apreensão de novos

Memorare, Tubarão, v. 8, n. 1, jan./jun. 2021. ISSN: 2358-0593 
sentidos, até então, estranhos e distantes do sentido primário (homofóbico) atribuído à palavra 'viado'. Tanto as pessoas não heterossexuais, quanto as pessoas homossexuais que utilizam essa expressão com uma intenção que não seja a de ofender um sujeito homossexual, além de ressignificarem o conteúdo inicial circunscrito na palavra, eles passaram a absorver esse novo conteúdo e o reproduzirem em seus coletivos de forma que os novos sentidos atribuídos a palavra se tornaram conteúdos próximos, comuns e familiares para eles.

Percebe-se que houve um determinado desmembramento de significados em relação a palavra 'viado'. A possibilidade de produção de sentidos diferentes ao sentido homofóbico atribuído à palavra demonstra o quanto as representações sociais, através dos processos de ancoragem e objetivação, podem influenciar na transformação de ideias, sentidos, valores, condutas e comportamentos frente a determinado objeto.

Observa-se o quanto as representações sociais sobre a homossexualidade podem ser utilizadas tanto para promover o preconceito homofóbico por meio da utilização da palavra 'viado' como xingamento a homossexuais masculinos, quanto para evidenciar um sentimento de simpatia e "camaradagem", entre homens heterossexuais. Dessa forma, fica claro o quanto a homofobia está vinculada, diretamente, a identidade de alguns grupos que a exercem. Isto porque, algumas pessoas heterossexuais podem usar a mesma palavra, tanto para reafirmar os conteúdos grupais presentes em seu coletivo - utilizar a palavra 'viado' como gíria ou expressão que demonstre amizade e coleguismo -, quanto para demarcar em seu grupo os conteúdos que não fazem parte dele - utilizar a mesma palavra como ofensa ou xingamento a homens homossexuais.

\section{Considerações finais}

Chegamos ao fim deste ensaio com a indicação de que ainda há muito o que 'andar' frente às diversas facetas da violência que acontece para com as pessoas não cisgêneras e não heterossexuais. Por isso, este estudo se caracterizou por trazer a cena, com ênfase em uma expressão, para discutir como a violência pode se expressar na simples, mas intencional, forma de nomear sujeitos, identidades e formas de se expressar.

Isso foi possível a partir da nossa busca abalizada pela Teoria das Representações Sociais que entende que os saberes presentes na sociedade têm marcas do social, do que é partilhado e dos sistemas de normas e ideais de sujeito presentes. Isso não está desatrelado da história e dos fatos cotidianos e contextuais aos quais aquela sociedade está vinculada. Estes saberes, formas de pensar e de agir se movimentam, se renovam e se cristalizam permitindo que os indivíduos entendam os fenômenos, ideias ou proposições. Em especial, observamos o quanto as representações sociais podem produzir novos significados e concepções para determinados objetos.

Entendemos que se as RS são mecanismos de produção e reprodução de determinados tipos de comportamentos, condutas, valores e ideais que estão fixados na sociedade. Compreendeu-se, portanto, que a produção da violência homofóbica, presente nos 
sentidos pejorativos da palavra 'viado' - por exemplo - é

operacionalizada por traços, pensamentos, julgamentos e pré-

concepções que podem levar à homofobia por parte de alguns coletivos da sociedade. Para combater a homofobia é preciso que exista um movimento nas formas de pensar, sentir e agir sobre a homoafetividade masculina, vê-la como possível, comum e, sobretudo, como algo natural para nossa sociedade.

Mesmo que este artigo tenha se centrado na questão da violência homofóbica contra homens gays, segue de igual importância o estudo e a aprofundamento sobre as formas de expressão da homofobia para outros sujeitos que se identificam com outras letras da sigla LGBTQIA+. Urge discutir como as nossas - aqui enquadramos todas as pessoas da nossa sociedade - tem nomeado tais sujeitos, e como tais nomeações têm prejudicado a vida de sujeitos e sujeitas não heterossexuais e não cisgêneros. É necessário visibilizar estas minorias, assim como é necessário trazer à tona as violências que elas sofrem cotidianamente.

Por outro lado, baseando-nos na Teoria das Representações Sociais foi possível compreender o quanto a sociedade estabeleceu relações dicotômicas com o significado pejorativo da expressão 'viado', de modo que um passou a nutrir a carga homofóbica do outro. Pensa-se que algumas pessoas entendem que a palavra 'viado' é um termo pejorativo que caracteriza um homossexual masculino, as quais imprimem através dessa expressão a ideia de que "ser gay é errado" é "contra os padrões naturais" ou é algo "desviante". Todavia, é possível compreender que quando coletivos não heterossexuais ressignificam essa palavra, conferindo-lhe um sentido, completamente, diferente do primeiro, eles estão buscando produzir outras representações sociais sobre a homossexualidade, como forma, inclusive, de desconstruir, enfrentar, ou se posicionar frente aos valores e ideais compartilhados socialmente que acreditam que a homossexualidade está vinculada a algo errado ou inferior.

Enfim, é necessário afirmar que a discussão fomentada através dessa produção não se encerra aqui. Ao contrário, os autores dessa obra incentivam e apoiam a construção de outros materiais que discutam a temática, a fim de que as pessoas possam encontrar nas produções científicas que discorrem sobre as mais variadas formas de homofobia, apoio, referencial e possibilidades de compreensão acerca de como a homofobia pode ser estimulada ou enfrentada.

\section{Referências}

ALMEIDA, M. V. Senhores de Si. Uma interpretação antropológica da masculinidade. Lisboa, Fim de Século Edições, 2018.

ALVES. M. A. J. Representações sociais: desenvolvimentos atuais e aplicações à educação. In: CANDAU, V. M. (Org.). Linguagem: espaços e tempo no ensinar e aprender. In: ENCONTRO NACIONAL DE DIDÁTICA E PRÁTICA DE ENSINO (ENDIPE), 10., Rio de Janeiro. Anais. Rio de Janeiro: LP\&A, 2000.

ARANHA, A. J. Dicionário Brasileiro de Insultos. São Paulo: Ateliê Editorial, 2002.

BRASIL. Constituição da República Federativa do Brasil de 1988..Lei n.7.716 de 5 janeiro de 1989. Define os crimes resultantes de preconceito de raça ou de cor, texto 
atualizado pela lei 9.459, de 15 maio de 1997. Diário Oficial da União, Poder Executivo, Brasília, DF, 15 de set. 2016. http://www.planalto.gov.br/ccivil_03/ leis/L7716.htm.

BUTLER, J. Critically queer. GLQ: A Journal of Lesbian and Gay Studies, 1(1), 17-32, 1993.

CARMO, E.B.; RESENDE, F.M. Representações sociais e o processo de construção de identidades homossexuais: identificando e comparando as representações de homens homossexuais e homens heterossexuais sobre a homossexualidade masculina. Revista da Graduação em Psicologia da PUC Minas, v. 3, n. 5, jun. 2018.

CHAMON, E.M. Q.O. Representação Social da pesquisa pelos doutorandos em ciências exatas. Estudos e Pesquisas em Psicologia, Rio de Janeiro, Ano 6, n. 2, jul. 2006.

CITADDIN, L.; LINO, Z. J. Análise etimológica de palavras com sentido pejorativo em relação a membros da comunidade LGBTQI+ . Revista Linguagem, Ensino e Educação, Criciúma, v. 2, n. 1, jan. - jul. , p . 1-7, 2018

DANTAS, M. B. 0 masculino na mídia: repertórios sobre masculinidade na propaganda televisiva brasileira. Dissertação de Mestrado, Psicologia Social, PUC-SP, 1997.

DIETER, C. T. As raízes históricas da homossexualidade, os avanços no campo jurídico e o prisma constitucional. IBDFAM. 2018. Disponível em: http://www.ibdfam.org.br/_img/artigos/As\%20ra\%C3\%ADzes\%20hist\%C3 \%B3ricas\%2012_04_2012.pdf. Acesso em: 31 abr. 2021

FIGUEIRÓ, M. N. D. (Org.). Educação sexual: múltiplos temas, compromisso comum. Londrina: UEL, 2009.

FOUCAULT, M. História da sexualidade 2: 0 uso dos prazeres. Rio de Janeiro: Graal, 1984.

JESUS, C. C., História e Teoria Queer: possibilidades nas margens. Boletim Historiar, vol. 07, n. 01, Jan./Abr. 2020, p. 32-41.

JODELET, D. Representações sociais: um domínio em expansão. In D. Jodelet (Ed.), As representações sociais (pp. 17-44). Rio de Janeiro: UERJ, 2001.

GAVAZZONI, K.; SOUZA, S. M. Construção do discurso homofóbico em redes sociais. In: IX SEMINÁRIO DO ALUNOS DE PÓS-GRADUAÇÃO DO INSTITUTO DE LETRAS DA UFF - ESTUDO DE LINGUAGEM, 2018, Niterói. IX Sappil UFF, 2018. v. 1. p. 496-510.

LADEIRA, T. A. 0 gay, o "viado" e a "bicha" pão com ovo: desconstruindo estereótipos de gênero e sexualidade. V CEDUCE. Campina Grande - PB. v. 2, 2018. p. 2-9. 2018.

LAU, H. D.; FERREIRA, W.J. Estereótipos da comunidade gay enquanto ser virtual. In: VII ENPECOM - Encontro de Pesquisa em Comunicação: Comunicação \& Gênero, 2015, Curitiba. Anais do VII ENPECOM - Encontro de Pesquisa em Comunicação: Comunicação \& Gênero. Curitiba: UFPR, 2015. v. 7. p. 503-522.

MOSCOVICI, S. A psicanálise, sua imagem e seu público. Tradução de Sonia Fuhrmann. Petrópolis: Vozes, 2012. 
MOSCOVICI, S. A representação social da psicanálise. Tradução de Cabral. Rio de Janeiro: Zahar, 1978.

MOSCOVICI, S. Representações sociais: investigações em psicologia social. Petrópolis, RJ: Vozes, 2015.

NASCIMENTO, F. E. M. Agrupamentos de travestis e transexuais encarceradas no Ceará, Brasil. Rev. Estud. Fem. vol. 28 no.1 Florianópolis 2020 Epub Maio 15, 2020.

NETO, I.; FIRMINO, I.; PAULINO, P. R. V. A construção social do estigma em masculinidade: uma revisão de literatura. V.4. n.1. 2019

NEVES, J. F., BATISTA, S. E., LEVANDOSKI, G. Visões preconceituosas e homofóbicas de estudantes do ensino médio. v. 22. Ulbra: Rio Grande do Sul, 2020.

ORGANIZAÇÃO DAS NAÇÕES UNIDAS. Declaração Universal dos Direitos Humanos. Adotada e proclamada pela resolução 217 A (III) da Assembleia Geral das Nações Unidas em 10 de dezembro de 1948. Disponível em: <http://unesdoc.unesco.org/images/0013/001394/139423por.pdf>. Acesso em 13 de Maio de 2020.

PETERS, C. E. M. Religião e representações da homossexualidade em escolas públicas de Penápolis - SP (1990-2009). Memorare, [S.l.], v. 4, n. 2-II, p. 165-186, ago. 2017.

REIS T. Avanços e desafios para os direitos humanos das pessoas LGBT. In: Vieira TR, editor. Minorias sexuais: direitos e preconceitos. Brasília: Consulex; 2012. p. 55-68.

RIBEIRO, L. P.; ROCHA, M. I. A.; Identidades em movimento: estudos sobre discentes que se formam para atuar nas escolas do campo. Representações sociais, identidade e preconceito: Estudos de Psicologia Social. 1. ed. Belo Horizonte: Autêntica Editora, 2019.

ROSA, V. M.; SOUZA, M. O.; BORGES, A. M. Preconceito contra a mulher na educação física escolar no nono ano. Prâksis. Novo Hamburgo; a. 17 n. 1 jan./abr. 2020

SARAIVA, L. A.S.; SANTOS, L. T.; PEREIRA, J. R. Heteronormatividade, Masculinidade e Preconceito em Aplicativos de Celular: 0 Caso do Grindr em uma Cidade Brasileira. BBR, Braz. Bus. Rev. Vitória, v. 17, n. 1, p. 114-131, Feb. 2020.

SILVA et al. A violência homofóbica no Rio de Janeiro a partir do jornalismo digital. Interface (Botucatu). 2020, v. 24.

SPENCER. C. Homossexualidade: uma história. Rio de Janeiro: Record, 1999.

TERTO JR., V. Homossexualidade e saúde: desafios para a terceira década de epidemia de HIV/AIDS. Horiz. antropol., Porto Alegre, v. 8, n. 17, p. 147-158, June 2002.

TONIETTE, M. A. Um breve olhar histórico sobre a homossexualidade. Revista Brasileira de Sexualidade Humana, São Paulo, v. 17, n. 1, 2006.

VERBICARO S., D. 0 estudo da orientação homossexual pensado nos direitos humanos e na sociedade brasileira. Bagoas - Estudos gays: gêneros e sexualidades, v. 13, n. 20, 21 ago. 2019. 
WAGNER, W. Sócio-gênese e características das representações sociais. In A. S. P. Moreira, \& D. C. de Oliveira. (Eds.), Estudos interdisciplinares de representação social (pp. 3-25). Goiânia: AB, 1998.

ZAMBONI, M. Travestis e Transexuais privadas de liberdade: a (des)construção de um sujeito de direitos. Revista Euroamericana de Antropologia (REA), № 2, 2016.

Artigo enviado em: 19/06/2020. Aprovado em: 09/12/2020. 